\title{
Comparison between Upper Mini Sternotomy and Full Sternotomy in Aortic Valve Replacement
}

\author{
Morsi Ameen Aly, Mohammed Ahmed Amr, El-Sayed Ahmed Fayad, Osama Elsayed Aly Mohammed* \\ Cardiothoracic Surgery Department, Faculty of Medicine, Suez Canal University \\ *Corrosponding author: Osama Elsayed Aly Mohammed, E-mail: ossamma_alex@yahoo.com
}

\begin{abstract}
Background: aortic valve disease is common and its prevalence increases with age. For people over the age of 75 years, the prevalence of aortic stenosis (AS) is 5\%. More than one in eight people over the age of 75 have moderate or severe valve disease. Aim of the Work: the aim of this study was to compare the short term results of aortic valve replacement through upper mini sternotomy and full sternotomy. Patients and Methods: This study was a prospective randomized controlled clinical trial. The study was conducted at Suez Canal University Hospital in the cardiothoracic operating rooms and inward after approval of Research and Ethics Committees. The study included 50 patients having aortic valve disease presented to Suez Canal University Hospital, cardiothoracic outpatient clinic for isolated aortic valve replacement. Results: The mean age of patients in Full Sternotomy in Aortic Valve Replacement (FSAVR) group was $33.48 \pm 17.74$ while it was $32.03 \pm 15.29$ in Mini Sternotomy in Aortic Valve Replacement (MSAVR) group which showed insignificance difference ( $p>0.05)$. (20-29y) was the most frequent age group in both study groups (28\% in FSAVR group and 32\% in MSAVR group). No significance different found $(\mathrm{p}>0.05)$ according to gender in both group. Male gender was the most frequent in both group (56\% in FSAVR group and 64\% in MSAVR group).

Conclusion: Mini Sternotomy (MS) can be considered as excellent option with favorable outcomes that should be considered part of the routine practice of cardiac surgeons in the modern era.
\end{abstract}

Keywords: Upper Mini Sternotomy, Full Sternotomy, Aortic Valve Replacement.

\section{INTRODUCTION}

Aortic valve disease is common and its prevalence increases with age. For people over the age of 75 years, the prevalence of aortic stenosis (AS) is $5 \%$. More than one in eight people over the age of 75 have moderate or severe valve disease ${ }^{(1)}$.

The overall prevalence aortic regurgitation (AR) in men was $13 \%$ and in women $8.5 \%$. However, most of the AR in this population was trace or mild in severity; moderate or severe AR was rare. Multiple logistic regression analysis revealed age and male gender to be predictors of $\mathrm{AR}^{(2)}$.

aortic valve replacement (AVR) using upper mini sternotomy was first described in 1993, and subsequently popularized in 1996 and 1997 as an alternative to conventional full sternotomy (FS) for patients with isolated $\mathrm{AVR}^{(3)}$.

Favorable results have led mini AVR to become a standard procedure in many high volume centers ${ }^{(4)}$.

In addition to the smaller incision and improved cosmetic outcome of cardiac surgery, numerous studies report a reduction in post-operative bleeding, transfusion requirements, rates of atrial fibrillation, length of mechanical ventilation, length of intensive care unit (ICU) and hospital stay, as well as postoperative pain with no difference in mortality ${ }^{(5)}$.

on the other side, The upper mini-sternotomy have a longer cardiopulmonary bypass and aortic crossclamp times, which in general tend to predict worse outcomes in cardiac surgery ${ }^{(6)}$.
The upper mini sternotomy limits the ability to control left ventricular distention, and some surgeons do not use it for severe aortic insufficiency ${ }^{(7)}$.

\section{AIM OF THE WORK}

The aim of this study is to compare the short term results of aortic valve replacement through upper mini sternotomy and full sternotomy.

\section{PATIENTS AND METHODS}

\section{Type of study}

This study was a prospective randomized controlled clinical trial.

\section{Setting and timing:}

The study was conducted at Suez Canal University Hospital in the cardiothoracic operating rooms and inward after approval of Research and Ethics Committees.

\section{Study population:}

The study included 50 patients having aortic valve disease presented to Suez Canal University Hospital cardiothoracic outpatient clinic for isolated aortic valve replacement.

To qualify for participation in this trial, the patients have to meet the following inclusion and exclusion criteria. 
Inclusion criteria:

1) Patients with isolated aortic valve disease in need for surgical intervention.

2) Patients with no co-morbidities.

\section{Exclusion criteria:}

Patients with any of the following criteria were excluded from the study:

1) Redo aortic valve replacement.

2) Patients who need for concomitant $\mathrm{CABG}$ or combined other cardiac surgery e.g. (severe tricuspid regurgitation).

Randomization:

We used simple random samples.

Methods of Data Collection:

- During the pre-procedural visit, both techniques were explained to all patients including benefits and complications of each.

- After obtaining approval by the Ethics Committee of the Suez Canal University Hospital, and written informed patient consent with an explanation regarding the purpose, effects, technique and complications, 50 patients having isolated aortic valve disease were included.

- Patients were randomly assigned into one of two equal groups on alternative basis;

Group (1): (25 patients) were surgically treated with the standard full sternotomy

Group (2): (25 patients) were surgically treated with upper mini sternotomy.

\section{Preoperative assessment:}

\section{History and risk factors:}

From all patients in the 2 groups we will take a full clinical history and risk factors including: age, sex, smoking, dyspnea, diabetes mellitus, hypertension, hypercholesterolemia and respiratory problem.

\section{Examination:}

Full clinical examination will be done for all patients including general examination, abdominal examination, chest examination and full cardiac examination.

\section{Investigations:}

- All patients were submitted to routine tests including: complete blood count, liver function tests, kidney function tests, coagulation profile, serum proteins and blood sugar.

$\circ$ Chest $x$ ray.

- ECG.

- Echocardiography and trans-esophageal echocardiography (TEE).

- Coronary angiography: was done for all the patients above 35 years preoperatively for exclusion criteria.

- Carotid duplex: was done for all patients over 50.

o Post-Operative follow up and outcomes:

- Postoperative assessment:

- Every patient was subjected to:

- Clinical assessment for postoperative morbidity.

- Mechanical ventilation with the assessment of the time of ventilation.

- The use of inotropic drugs.

- Occurrence of new arrhythmias.

- Total ICU stay in hours.

- Total hospital stay in days.

- Total transfused blood units.

- Need for re-exploration.

Investigations:

1) Laboratory investigations:

all patients were submitted in the early postoperative period to routine laboratory tests including complete blood picture, liver and renal function tests, lipid and coagulation profiles, serum proteins, blood sugar tests (fasting and postprandial) and serum electrolytes ( $\mathrm{Na}$ and $\mathrm{K}$ ).

2) Echocardiography: before discharge or when the patient's condition is unstable.

3) Plain chests $X$ - ray: at the same day of surgery.

\section{Statistical Analysis:}

Data was analyzed using SPSS 16. Mean + standard deviation was computed for age, weight and height. Chi square test was applied to compare cardiovascular side effects. Repeated measures analysis of variance (ANOVA) was used to compare effects like heart rate, systolic and diastolic blood pressures of the two groups. P-value of 0.05 or less was considered statistically significant. 
RESULTS

Table (1): comparison between the two study groups in terms of socio- demographic characteristics and preoperative clinical findings

\begin{tabular}{|c|c|c|c|c|c|c|}
\hline \multirow{2}{*}{\multicolumn{2}{|c|}{ Variable }} & \multicolumn{2}{|c|}{ FSAVR Group } & \multicolumn{2}{|c|}{ MSAVR Group } & \multirow{2}{*}{$\begin{array}{c}P \\
\text { Value }\end{array}$} \\
\hline & & $\mathbf{N}$ & $\%$ & $\mathbf{N}$ & $\%$ & \\
\hline \multirow{7}{*}{ Age (year) } & $>20$ & 6 & $24 \%$ & 5 & $20 \%$ & \multirow{7}{*}{0.997} \\
\hline & $20-29$ & 7 & $28 \%$ & 8 & $32 \%$ & \\
\hline & $30-39$ & 5 & $20 \%$ & 6 & $24 \%$ & \\
\hline & $40-49$ & 3 & $12 \%$ & 2 & $8 \%$ & \\
\hline & $50-59$ & 2 & $8 \%$ & 2 & $8 \%$ & \\
\hline & <60y & 2 & $8 \%$ & 2 & $8 \%$ & \\
\hline & Mean \pm SD & \multicolumn{2}{|c|}{$33.48 \pm 17.74$} & \multicolumn{2}{|c|}{$32.03 \pm 15.29$} & \\
\hline \multirow[b]{2}{*}{ Gender } & Male & 14 & $56 \%$ & 16 & $64 \%$ & \multirow[b]{2}{*}{0.56} \\
\hline & Female & 11 & $44 \%$ & 9 & $36 \%$ & \\
\hline \multicolumn{2}{|l|}{ Weight $(\mathrm{Kg})$} & \multicolumn{2}{|c|}{$67.34 \pm 19.59$} & \multicolumn{2}{|c|}{$62.33 \pm 21.21$} & \\
\hline \multicolumn{2}{|l|}{ Hight (cm) } & \multicolumn{2}{|c|}{$168.6 \pm 4.16$} & \multicolumn{2}{|c|}{$169.4 \pm 2.44$} & \multirow{6}{*}{0.49} \\
\hline \multirow{5}{*}{$\begin{array}{l}\text { BMI } \\
\text { strata }\end{array}$} & $>21$ & 8 & $32 \%$ & 13 & $52 \%$ & \\
\hline & $21-24.9$ & 7 & $28 \%$ & 4 & $16 \%$ & \\
\hline & $25-30$ & 4 & $16 \%$ & 4 & $16 \%$ & \\
\hline & $<30-35$ & 6 & $24 \%$ & 4 & $16 \%$ & \\
\hline & Mean \pm SD & \multicolumn{2}{|c|}{$23.76 \pm 7$} & \multicolumn{2}{|c|}{$21.67 \pm 7.19$} & \\
\hline \multirow{4}{*}{$\begin{array}{l}\text { NYHA } \\
\text { class }\end{array}$} & I & 5 & $20 \%$ & 6 & $24 \%$ & \multirow{4}{*}{0.95} \\
\hline & II & 9 & $36 \%$ & 8 & $32 \%$ & \\
\hline & III & 7 & $28 \%$ & 8 & $32 \%$ & \\
\hline & IV & 4 & $16 \%$ & 3 & $12 \%$ & \\
\hline \multirow{3}{*}{$\mathrm{EF} \%$} & $>40$ & 6 & $24 \%$ & 8 & $32 \%$ & \multirow{3}{*}{0.53} \\
\hline & $\leq 40$ & 19 & $76 \%$ & 17 & $68 \%$ & \\
\hline & Mean \pm SD & \multicolumn{2}{|c|}{$47.7 \pm 8.58$} & \multicolumn{2}{|c|}{$46.08 \pm 14.57$} & \\
\hline
\end{tabular}

Table (2): Comparison between Upper Mini Sternotomy and Full Sternotomy in operative data

\begin{tabular}{|c|c|c|c|c|c|c|}
\hline & \multirow{2}{*}{ Variable } & \multicolumn{2}{|c|}{ FSAVR Group } & \multicolumn{2}{|c|}{ MSAVR Group } & \multirow{2}{*}{$\begin{array}{c}\mathbf{P} \\
\text { Value }\end{array}$} \\
\hline & & $\mathbf{N}$ & $\%$ & $\mathbf{N}$ & $\%$ & \\
\hline \multirow{2}{*}{ Operative procedure } & AVR & 21 & $84 \%$ & 21 & $84 \%$ & \\
\hline & AVR + ARA & 4 & $16 \%$ & 4 & $16 \%$ & \\
\hline \multicolumn{2}{|l|}{ Length of skin wound $(\mathrm{cm})$} & \multicolumn{2}{|c|}{$18.68 \pm 2.75$} & \multicolumn{2}{|c|}{$8.36 \pm 1.3$} & 0.001 \\
\hline \multirow{6}{*}{ Operative times (min) } & $\begin{array}{l}\text { Opening of chest, preparation and } \\
\text { cannulation }\end{array}$ & \multicolumn{2}{|c|}{$31.92 \pm 5.79$} & \multicolumn{2}{|c|}{$40.22 \pm 8.96$} & 0.24 \\
\hline & Cross clamping time (min) & \multicolumn{2}{|c|}{$63.72 \pm 18.28$} & \multicolumn{2}{|c|}{$63.44 \pm 17.52$} & 0.96 \\
\hline & $\begin{array}{l}\text { Cardiopulmonary bypass time } \\
\text { (min) }\end{array}$ & \multicolumn{2}{|c|}{$72.05 \pm 12.97$} & \multicolumn{2}{|c|}{$76.7 \pm 13.26$} & 0.001 \\
\hline & Hemostasis & \multicolumn{2}{|c|}{$23.25 \pm 5.75$} & \multicolumn{2}{|c|}{$10.52 \pm 1.9$} & 0.001 \\
\hline & Chest closure & \multicolumn{2}{|c|}{$11.18 \pm 2.08$} & \multicolumn{2}{|c|}{$12.18 \pm 2.17$} & 0.09 \\
\hline & Total operative time (min) & \multicolumn{2}{|c|}{$164.53 \pm 28.84$} & \multicolumn{2}{|c|}{$201.24 \pm 25.07$} & 0.001 \\
\hline \multirow{2}{*}{ Need for blood transfusion } & $\begin{array}{l}\text { Frequency of } \\
\text { need for blood transfusion }\end{array}$ & 13 & $52 \%$ & 6 & $24 \%$ & \\
\hline & Number of transfused units & \multicolumn{2}{|c|}{$0.98 \pm 1.01$} & \multicolumn{2}{|c|}{$0.32 \pm 0.62$} & 0.01 \\
\hline \multicolumn{2}{|l|}{ Intraoperative Rt. IMA injury } & 0 & $0 \%$ & 2 & $8 \%$ & \\
\hline
\end{tabular}


Table (3): Comparison between Upper Mini Sternotomy and Full Sternotomy in post-operative (PO) data

\begin{tabular}{|c|c|c|c|c|c|c|}
\hline \multirow{2}{*}{\multicolumn{2}{|c|}{ Variable }} & \multicolumn{2}{|c|}{ FSAVR Group } & \multicolumn{2}{|c|}{ MSAVR Group } & \multirow{2}{*}{$\begin{array}{c}P \\
\text { Value }\end{array}$} \\
\hline & & $\mathbf{N}$ & $\%$ & $\mathbf{N}$ & $\%$ & \\
\hline \multirow{4}{*}{ Amount of 1st PO day wound drainage (ml) } & $>250$ & 0 & $0 \%$ & 5 & $20 \%$ & \multirow{4}{*}{0.001} \\
\hline & $250-500$ & 10 & $40 \%$ & 19 & $76 \%$ & \\
\hline & $<500$ & 15 & $60 \%$ & 1 & $4 \%$ & \\
\hline & Mean \pm SD & \multicolumn{2}{|c|}{$532.28 \pm 105.22$} & \multicolumn{2}{|c|}{$298.93 \pm 80.48$} & \\
\hline \multicolumn{2}{|l|}{ Need for re-exploration } & 3 & $12 \%$ & 1 & $4 \%$ & 0.43 \\
\hline \multicolumn{2}{|l|}{ Duration of mechanical ventilation (hour) } & \multicolumn{2}{|c|}{$7.31 \pm 0.81$} & \multicolumn{2}{|c|}{$6.75 \pm 0.86$} & 0.03 \\
\hline \multicolumn{2}{|l|}{ Mean duration of ICU stay (days) } & \multicolumn{2}{|c|}{$2.17 \pm 0.57$} & \multicolumn{2}{|c|}{$1.92 \pm 0.44$} & 0.11 \\
\hline \multirow{4}{*}{ Mean pain scores } & 6-hr afterward transfer & \multicolumn{2}{|c|}{$6.78 \pm 1.36$} & \multicolumn{2}{|c|}{$4.88 \pm 0.75$} & 0.001 \\
\hline & \begin{tabular}{|l|} 
12-hr afterward \\
transfer
\end{tabular} & \multicolumn{2}{|c|}{$4.91 \pm 1.28$} & \multicolumn{2}{|c|}{$3.45 \pm 0.89$} & 0.001 \\
\hline & $\begin{array}{l}\text { 24-hr afterward } \\
\text { transfer }\end{array}$ & \multicolumn{2}{|c|}{$3.64 \pm 1.22$} & \multicolumn{2}{|c|}{$2.83 \pm 0.87$} & 0.012 \\
\hline & $\begin{array}{l}\text { 36-hr afterward } \\
\text { transfer }\end{array}$ & \multicolumn{2}{|c|}{$3.47 \pm 1.6$} & \multicolumn{2}{|c|}{$1.87 \pm 0.55$} & 0.001 \\
\hline
\end{tabular}

Table (4): Comparison between Upper Mini Sternotomy and Full Sternotomy in post-operative (PO) complication

\begin{tabular}{|c|c|c|c|c|c|c|}
\hline \multirow{2}{*}{\multicolumn{2}{|c|}{ Variable }} & \multicolumn{2}{|c|}{ FSAVR Group } & \multicolumn{2}{|c|}{ MSAVR Group } & \\
\hline & & $\mathbf{N}$ & $\%$ & $\mathbf{N}$ & $\%$ & \\
\hline \multirow{3}{*}{$\begin{array}{l}\text { Sternal } \\
\text { wound infection }\end{array}$} & Superficial & 4 & $16 \%$ & 3 & $12 \%$ & \multirow{3}{*}{0.48} \\
\hline & Deep & 2 & $8 \%$ & 1 & $4 \%$ & \\
\hline & No & 19 & $76 \%$ & 21 & $84 \%$ & \\
\hline \multicolumn{2}{|l|}{ Atrial fibrillation } & 7 & $28 \%$ & 5 & $20 \%$ & 0.51 \\
\hline
\end{tabular}

Table (5): Pre-and post- operative NYHA

\begin{tabular}{|l|l|c|c|c|c|}
\hline \multirow{2}{*}{ Variable } & \multicolumn{2}{c|}{ FSAVR Group } & \multicolumn{2}{c|}{ MSAVR Group } \\
\cline { 3 - 6 } \multicolumn{2}{c|}{} & $\begin{array}{c}\text { Pre- operative } \\
(\%)\end{array}$ & $\begin{array}{c}\text { Post- operative } \\
(\%)\end{array}$ & $\begin{array}{c}\text { Pre- operative } \\
(\%)\end{array}$ & $\begin{array}{c}\text { Post- operative } \\
(\%)\end{array}$ \\
\hline \multirow{3}{*}{$\begin{array}{l}\text { NYHA } \\
\text { Score }\end{array}$} & I & $5(20 \%)$ & $8(32 \%)$ & $6(24 \%)$ & $14(56 \%)$ \\
\cline { 2 - 6 } & II & $9(36 \%)$ & $15(60 \%)$ & $8(32 \%)$ & $10(40 \%)$ \\
\cline { 2 - 6 } & III & $7(28 \%)$ & $2(8 \%)$ & $8(32 \%)$ & $1(4 \%)$ \\
\cline { 2 - 6 } & IV & $4(16 \%)$ & $0(0 \%)$ & $3(12 \%)$ & $0(0 \%)$ \\
\hline
\end{tabular}

Table (6): Comparison between Upper Mini Sternotomy and Full Sternotomy in wound satisfaction scores

\begin{tabular}{|c|c|c|c|c|c|c|}
\hline \multirow{2}{*}{\multicolumn{2}{|c|}{ Variable }} & \multicolumn{2}{|c|}{ FSAVR Group } & \multicolumn{2}{|c|}{ MSAVR Group } & \multirow{2}{*}{$\begin{array}{c}\mathbf{P} \\
\text { Value }\end{array}$} \\
\hline & & $\mathbf{N}$ & $\%$ & $\mathbf{N}$ & $\%$ & \\
\hline \multirow{5}{*}{ Satisfaction score } & Very satisfied & 4 & $16 \%$ & 9 & $36 \%$ & \multirow{5}{*}{0.06} \\
\hline & Satisfied & 8 & $32 \%$ & 11 & $44 \%$ & \\
\hline & Dissatisfied & 8 & $32 \%$ & 3 & $12 \%$ & \\
\hline & Very dissatisfied & 5 & $20 \%$ & 2 & $8 \%$ & \\
\hline & Mean \pm SD & \multicolumn{2}{|c|}{$1.92 \pm 0.91$} & \multicolumn{2}{|c|}{$2.56 \pm 1$} & \\
\hline
\end{tabular}




\section{DISCUSSION}

In this study, we compared between ministernotomy (MS) and full sternotomy (FS) approaches of aortic valve replacement (AVR) surgery by evaluating both intra-operative (IO) and post-operative (PO) outcomes. Although the benefits of MS have been widely reported, widespread adoption has not occurred and some skeptics are calling for additional evidence ${ }^{(8)}$. We present a robust, propensity-matched comparison of aortic valve replacement via MS and FS approaches from Suez Canal University hospital. The major findings in our study are that patients undergoing isolated AVR via MS had less time on the ventilator, shorter ICU and hospital length of stays with comparable short and long-term survival compared to the FS group. These findings corroborate other reports demonstrating similar in-hospital benefits of mini AVR ${ }^{(9)}$. Numerous studies have shown that these improved in-hospital outcomes likely result from decreased post-operative pain, facilitating quicker return of pulmonary function and mobilization ${ }^{(\mathbf{1 0})}$.

In terms of intra-operative outcomes, our study results reported that MS approach provided several intraoperative advantages over FS approach in AVR surgery such as significant reduction of time needed for hemostasis, lower frequency of need for blood transfusion and consumption of fewer transfused blood units. These findings agree with those reported by Gilmanov et al. which reported half as many units transfused per patient in the MS group compared to FS patients. Interestingly, Gilmanov and colleagues reported no difference in reoperations for bleeding, a finding consistent with our own results. Along with increased transfusion requirements, blood loss in the first $24 \mathrm{~h}$ after surgery is higher with FS. These findings can be attributed to a simple principle that less dissection decreases the chance for bleeding and therefore minimizes transfusion requirements may also extend to reoperative surgery ${ }^{(\mathbf{1 1})}$.

our study showed that the main limitation for MS approach in AVR surgery was the narrow and unusual operative field this lead to consuming significantly longer operative time during MS approach compared to FS approach in AVR as a result of long preparation and cannulation time, long cardio- pulmonary bypass (CPB) time secondary to prolonged de-airing time and time consumed for insertion of substernal drain and pacemaker thread (10).

These findings agree with those reported by Olin \& Peterffy (11) who reported that the main disadvantage of MS approach in AVR in general is that it is difficult to master intra- and postoperative complications should they occur. Also, Kuralay et al. ${ }^{(12)}$ documented that MS approach for AVR was intimidating for many surgeons, not only for limited surgical exposure but also for the inability to complete de-airing the apex of the heart.

In agreement with our results, recent trials documented still persistency of such limitation; where Gilmanov et al. ${ }^{(13)}$ found CPB time was significantly longer with MS approach in AVR than conventional AVR. Glauber et al. documented that MS is limited by the longer CPB time, which have increases many concerns in high risk patients. However, results reported by Lim et al. Lim et al. showed that MS can be performed safely despite the longer ischemic time.

In terms of post-operative outcomes, patients in MS group experienced favorable post-operative course in comparison to FS patients in terms of significantly lower amount of 1st post-operative day wound drainage, and durations of mechanical ventilation and significantly lower PO pain scores.

Additionally, our study results reported significantly less duration of ICU admission postoperatively. These results agree with many results reported by recent studies comparing MS and right FS for AVR also show possible advantages to the MS, including less hospital length of stay ${ }^{(5)}$.

However, additional studies and data pooled from more than one institution are needed to confirm these results. Also, patients in MS group experienced more satisfactory immediate post- operative outcomes such as early in-hospital resumption of normal breathing without limitation and early return to physical activity. Additionally, MS patients showed significantly better NYHA scores compared to FS patients. Such improvement could be explained by the short sternal wound thus reducing pain secondary to respiratory movement. Also, patients having MS were allowed to sleep freely without limitation to supine position, owing to wound fixity provided by the lower part of the sternum thus excluding the possibility of sternal wound mal-union or overriding edges. Another advantage of MS over FS in AVR is the skin wound incision for MS was cosmetically better than for FS with significantly satisfaction scores compared to FSAVR patients. This finding can be mainly attributed to the significantly shorter length of skin wound and the lower frequency of sternal wound infection with MS than FS. In support of these findings, Shehada et al. reported better cosmetic results with MS compared to FSAVR. In terms of immediate post-operative mortality, there were no reported cases in both groups. Also, the frequency of post-operative sternal wound infection and need for re-exploration was non-significantly different between MS and FS 
groups. These results can be supported by those reported by Brown et al. ${ }^{(\mathbf{1 4})}$ who documented that MS can be performed safely for AVR, without increased risk of death or other major complication. Also, Totaro et al. documented that minimally invasive approach through upper MS is feasible and safe not only for isolated AVR but that it can also be utilized for a variety of complex surgical procedures.

The main strength of our study is its design. Being a randomized controlled trial study enabled us to overcome several disadvantages and biases of observational retrospective studies conducted before. In terms of our study limitations, our study represents a single center experience. While the propensity matching technique used has been well validated, a limitation of the methodology is that it cannot address bias introduced by unmeasured variables, thus it is possible our results reflect the influence of unknown factors other than the effect of the treatment on the treated. However, this design does allow us to evaluate a patient sample that is representative of the isolated AVR population at our institution, and our sample size was robust. Another disadvantage is the short duration of follow-up that cannot enable us to calculate whether there is a significant difference in overall survival or not.

\section{CONCLUSION}

In addition to the intrinsic cosmetic advantages, we have validated the essential clinical benefits of this MS technique, including decreased transfusion requirements, ventilation times, ICU and hospital length of stay without compromising short and longterm survival compared with conventional AVR via FS.

MS can be considered as excellent option with favorable outcomes that should be considered part of the routine practice of cardiac surgeons in the modern era.

\section{REFERENCES}

1. Nkomo VT, Gardin JM, Skelton TN, Gottdiener JS, Scott CG, Enriquez- Sarano M (2006): Burden of valvular heart diseases: a population-based study. Lancet, 368(9540):1005-11.

2. Singh JP, Evans JC, Levy D, Larson MG, Freed LA, Fuller DL, et al. (1999): Prevalence and clinical determinants of mitral, tricuspid, and aortic regurgitation (the Framingham Heart Study). Am J Cardiol., 83(6):897902.

3. Ito T, Maekawa A, Hoshino S, Hayashi Y (2013): Right infraaxillary thoracotomy for minimally invasive aortic valve replacement. Ann Thorac Surg., 96(2):715-7. 4. Candaele S, Herijgers $P$, Demeyere R, Flameng W, Evers G (2003): Chest pain after partial upper versus complete sternotomy for aortic valve surgery. Acta Cardiol., 58(1):17-21.

5. Glauber M, Miceli A, Gilmanov D, Ferrarini M, Bevilacqua S, Farneti PA et al. (2013): Right anterior minithoracotomy versus conventional aortic valve replacement: a propensity score matched study. J Thorac Cardiovasc Surg., 145(5):1222-6.

6. Dewey TM, Herbert MA, Ryan WH, Brinkman WT, Smith R, Prince SL et al. (2012): Influence of surgeon volume on outcomes with aortic valve replacement. Ann Thorac Surg., 93(4):1107-12.

7. Merk DR, Lehmann S, Holzhey DM, Dohmen P, Candolfi P, Misfeld M et al. (2015): Minimal invasive aortic valve replacement surgery is associated with improved survival: a propensity-matched comparison. Eur J Cardiothorac Surg., 47(1):11-7.

8. Bakir I, Casselman FP, Wellens F, Jeanmart H, De Geest R, Degrieck I et al. (2006): Minimally invasive versus standard approach aortic valve replacement: a study in 506 patients. Ann Thorac Surg., 81(5):1599-604.

9. Malaisrie SC, Barnhart GR, Farivar RS, Mehall J, Hummel B, Rodriguez E et al. (2014): Current era minimally invasive aortic valve replacement: techniques and practice. J Thorac Cardiovasc Surg., 147(1):6-14.

10. Bonacchi M, Prifti E, Giunti G, Frati G, Sani G (2002): Does ministernotomy improve postoperative outcome in aortic valve operation? A prospective randomized study. Ann Thorac Surg., 73(2):460-5.

11. Olin CL and Peterffy A (1999): Minimal access aortic valve surgery. Eur J Cardiothorac Surg., 15(1):S328.

12. Kuralay E, Demirkilic U, Oz BS, Cingoz F, Tatar H (2001): Simple de-airing technique for aortic valve replacement with upper ministernotomy. J Card Surg., 16(4):310-2.

13. Gilmanov D, Bevilacqua S, Murzi M, Cerillo AG, Gasbarri T, Kallushi E et al. (2013): Minimally invasive and conventional aortic valve replacement: a propensity score analysis. Ann Thorac Surg., 96(3):837-43.

14. Brown ML, Schaff HV, Lahr BD, Mullany CJ, Sundt TM, Dearani JA et al. (2008): Aortic valve replacement in patients aged 50 to 70 years: improved outcome with mechanical versus biologic prostheses. J Thorac Cardiovasc Surg., 135(4):878-84. 